\title{
Safety of Primary Intraocular Lens Insertion in Unilateral Childhood Traumatic Cataract
}

\author{
Kumar S, ${ }^{1}$ Panda $\mathrm{A}^{2}{ }^{2}$ Badhu $\mathrm{BP}^{3}{ }^{3}$ Das $\mathrm{H}^{4}$ \\ 'Department of Ophthalmology, Subharti Institute of Medical Sciences, Meerut, UP, India, ${ }^{2}$ Dr. Rajendra Prasad Centre for Ophthalmic \\ Sciences, All India Institute of Medical Sciences (AIIMS), New Delhi, India, ${ }^{3}$ Department of Ophthalmology, B P Koirala Institute of \\ Health Sciences, Dharan, Nepal, ${ }^{4}$ Siliguri Lions Netralaya, Hill Cart Road, Siliguri, India
}

\section{ABSTRACT}

This study analyzes the results of cataract surgery with primary intraocular lens implantation in unilateral childhood traumatic cataract following penetrating trauma and its long term follow up.

It is a hospital based study of 114 children (age 3-10 years) with unilateral traumatic cataract who underwent extracapsular cataract extraction/ lens aspiration with implantation of posterior chamber intraocular lens (IOL). Primary posterior capsulotomy (PPC) was performed in 57 eyes and the rest 57 were without PPC (NPPC). The patients were followed up at regular intervals for a period of 3 years.

Postoperative inflammation and pupillary capture were two frequent complications seen during postoperative period. Development of posterior capsular opacification (PCO) was $1 / 57,4 / 57$ at $8^{\text {th }}$ week and 7/30 and 14/39 at 6 months, in PPC and NPPC group, respectively. Best corrected visual acuity $(\mathrm{BCVA}) \geq 6 / 18$ was achieved in $50 \%$ of eyes at $8^{\text {th }}$ week post operatively and the same at 3 years with/without membranectomy/capsulotomy was evident in $73.3 \%$ of eyes.

Meticulous case selection with insersion of "in the bag IOL" and subjecting the traumatized cataractous eyes to primary posterior capsulotomy are factors responsible for optimal outcome in unilateral traumatic cataract in children.

Key words: childhood, intraocular lens, Nepal, traumatic cataract

\section{INTRODUCTION}

The major complications seen in paediatric IOL implantation are related to the severe post operative fibrinoid reaction exhibited by a child's eye. ${ }^{1,2}$ This is due to immature blood aqueous barrier which is more liable to disruption and has a low inherent fibrinolytic activity, encouraging the release of plasma proteins, clotting factors and fibrin into the anterior chamber. ${ }^{3}$ This is more so for a traumatic cataract where the child has been already exposed to non surgical trauma.

The aim of this study was to assess the safety of intraocular lens insertion in children aged 3 to 10 years with uniocular traumatic cataract.

\author{
Correspondence: \\ Dr. Sandeep Kumar \\ Deparment of Ophthalmology, \\ Subharti Institute of Medical Sciences, Meerut, UP, India. \\ Phone: +91-9837333592 \\ Email: sandeep_65@yahoo.com
}


Kumar et al. Safety of Primary Intraocular Lens Insertion in Unilateral Childhood Traumatic Cataract

\section{MATERIAL AND METHODS}

One hundred and fourteen patients with traumatic cataract between the age group of 3-10 years underwent extracapsular cataract extraction/aspiration and IOL insertion at BP Koirala Institute of Health Sciences between 1998-2001 (Figure 1). The eyes were randomly assigned to two groups, one where additional PPC was performed and the second was where PPC was not performed.

All the children were subjected to full ophthalmic examination with the help of torch and loupe. Slit lamp examination was carried out wherever possible. Both A \& B scan ultrasonography was performed in all, to rule out posterior segment pathology, evaluate the status of the cataract and posterior capsule and find out the axial length for IOL calculation as far as possible. Keratometry was carried out and the IOL power calculation was done using the modified SandersRetzlaff-Kraff (SRK II) formula. Eyes with central corneal opacity or any posterior segment pathology were excluded from the study. Parents were explained about the expected surgical outcome and assured to bring their children to the hospital for frequent follow up following surgery. All but one child were operated for extracapsular lens extraction and posterior chamber IOL implantation (ECCE + PC IOL). Only one child had anterior chamber IOL implantation (AC IOL) due to extensive preexisting posterior capsular defect. All the surgeries were performed under general anesthesia by surgeons having experience in paediatric cataract surgery with IOL implantation.

\section{SURGICAL PROCEDURE}

Intra ocular lens power calculations were performed by using the SRK II formula on the basis of axial length (A scan) and keratometeric value. If the keratometry was not possible, the normal contralateral keratometric value was used.

All the surgical steps were as per conventional IOL surgery except the fact that the site of incision was selected on the basis of preoperative keratometry value. The partial thickness scleral tunnel was made $1 \mathrm{~mm}$ posterior to the surgical limbus. With a crescent knife the sclera was dissected forward upto $1.5 \mathrm{~mm}$ inside the corneal tissue from the limbus. Two side ports were made at the cornea, adjacent to limbus, on both sides of the main tunnel for intraoperative manipulation. The anterior chamber was reached with a $3.2 \mathrm{~mm}$ disposable keratome. Anterior chamber was formed with $2 \%$ methyl cellulose. Either a horizontal envelope capsulotomy or a large continuous curvilinear capsulorhexis (CCC) or a small circular "can opener" capsulotomy were performed with a 26 gauge irrigating cystitome. If required, utrata forceps was used for CCC. This was followed by hydrodissection. A Simcoe irrigation aspiration cannula was used to clear the cortical matter. The capsular bag was filled with $2 \%$ methyl cellulose. This was followed by "in the bag" insertion of a $6.00 \mathrm{~mm}$, all PMMA biconvex IOL with a total diameter of $13 \mathrm{~mm}$. A “D” shaped anterior capsular flap was removed in the eyes with envelope capsulotomy. A peripheral iridectomy (PI) was performed in all. In 57 eyes, primary posterior central capsulotomy (PPC) was performed at the centre through PI. At the end of the surgery all the children received subconjunctival injection of $2 \mathrm{mg}$ gentamicin and $5 \mathrm{mg}$ dexamethasone. Besides, all the children were given $0.2 \mathrm{mg} / \mathrm{kg}$ of body weight intravenous dexamethasone. The eye remained bandaged till next morning. Postoperatively all the eyes received $0.3 \%$ ciprofloxacin drop four times a day, betamethasone drop (1\%) 6-8 times daily, neosporin ointment at bed time and tropicamide twice daily. Antiglaucoma therapy was instituted depending upon the indication. Topical medications were gradually reduced over the following six weeks. Conventional amblyopia therapy was given whenever indicated.

The patients were assessed daily following surgery while they were in the hospital. Parents were advised to bring the child one week after discharge, third week and sixth week. The sutures were removed at sixth week. Post operative evaluation included slit lamp biomicroscopy, indirect ophthalmoscopy and intraocular pressure measurement. Pre and post operative visual acuity was assessed either by Snellen's E chart /Stycar cube depending upon the age of the child. Refraction was performed after two weeks of suture removal and the final power was prescribed. Patients were advised to bring the children at six months, one year and thereafter annually.

\section{RESULTS}

Of 114 patients (Figure 1), 75 were boys and 39 girls (ratio 2:1), with a mean age of $6.92 \pm 2.04$ and $5.50 \pm 1.51$ years, respectively (overall mean age $6.64 \pm 1.98$ years). All the children had previous penetrating injuries and primary repair was performed in all, at least 3 months prior to cataract surgery. In $87(76.3 \%)$ eyes, the cataract was total and 27 $(23.7 \%)$ had partially absorbed cataracts. Ruptured anterior capsule was evident in $6(5.3 \%)$ and that of posterior capsule in $12(10.5 \%)$. All but one posterior capsular defect had fibrosed margin. The axial length as measured prior to surgery varied from 21.5-24.5 (Figure 2). In 113 (97\%) eyes the PC IOL was implanted either in the bag or in the sulcus depending on posterior capsular status and only one with a large posterior capsular defect required anterior vitrectomy followed by $A C I O L$ insertion. All the children came for regular 
Kumar et al. Safety of Primary Intraocular Lens Insertion in Unilateral Childhood Traumatic Cataract

follow up upto eighth week postoperative, 69 (60.5\%) came after 6 months and $56(49.1 \%)$ at 12 months. Anterior chamber reaction was graded between 0-3. Grading was done by $2 \times 1 \mathrm{~mm}$ slit beam at 45 degree oblique illumination with Zero $(0)$ as Absent / mild inflammation, 1 as cells in $A C \leq 50,2$ as presence of fibrin and 3 as presence of papillary membrane and that of posterior capsular opacification as 1-3 (Table 1). Twenty nine children $(25.4 \%)$ had severe anterior uveitis in the early postoperative period which could be controlled by frequent topical corticosteroid drop and ointment and cycloplegics in 17 and 12 patients with additional systemic corticosteroid therapy. Fifteen $(13 \%)$ eyes developed transient raised intra ocular pressure which could be controlled during first week but one eye with PC IOL developed intractable raised IOP and did not respond to maximal medical therapy. Trabeculectomy was performed and the eye became quiet with normal IOP.

Pupillary capture was observed in $5(9 \%)$ and 12 $(21 \%)$ eyes in PPC and NPPC group respectively. Of total 17 eyes with pupillary capture 12 were in sulcus fixated IOL and rest five were from in the bag group (2 envelope, 2 can opener and 1 capsulorhexis). Another $3 / 114(2.6 \%)$ eyes showed IOL tilt from sulcus fixated group.

All but one eye from PPC group and 4 eyes from NPPC group did not show clinically significant $\mathrm{PCO}$ at eighth week. The PCO was observed in $7 / 30$ and 14/39 at 6 months in the PPC and NPPC group respectively (Table 1).

At 12 months 20 children from PPC group and 36 from the NPPC group reported for follow up of which 4 had PCO in PPC group and 11 had in NPPC group. Of 41 PCO, 30 children were with PCO grade 2 and 3 were subjected to membrenectomy (21 eyes) or repeat surgical posterior capsulotomy through peripheral iridectomy ( 9 eyes).

Visual acuity unaided, with pin hole and after refraction was represented (Table 2, Figure 3). Hundred and five children (92\%) had their normal binocular function as tested by worth 4 dot test. There was no child with anisometropia, 9 children had amblyopia but responded to conventional amblyopia therapy. The comparative data of traumatic cataract surgery in children with regards to outcome (Table 3 ).

\section{DISCUSSION}

Management of uniocular cataract, more so in a child, is a great challenge. If the cataract is not operated or operated but not rehabilitated for a longer period there is a great possibility of development of amblyopia due to visual deprivation. In order to rehabilitate such eyes various modalities are available such as use of contact lens, spectacles, epikeratophakia and IOL insertion with their own limitations. While contact lens provides the easy adjustment of power, contact lens non compliance is a major problem in children. Aphakic spectacles are not suitable for children with unilateral aphakia. ${ }^{4}$ Epikeratophakia is another alternative for paediatric aphakia. However, this procedure was proved to be unsatisfactory in infants due to 2 limiting factors.

1. The grafted lenticule may remain hazy for an extended period of time placing these eyes at risk for amblyopia.

2. Continued axial elongation may cause a myopic shift. ${ }^{5}$

Intraocular lenses are the preferred and gold standard for uniocular traumatic cataract at any age and appears to be the most appreciable option in children as it provides a full time correction of an aphakic eye, the optics of which closely simulate the human crystalline lens. ${ }^{6-19}$ Moreover, the IOL is more affordable than the contact lens and it does not require specific post insertion care like in contact lens use, which is the most limiting factor in developing and underdeveloped countries. To avoid development of myopic shift during passage of time because of growth of the eye from $2.4 \mathrm{~mm}$ to $3.3 \mathrm{~mm}$ during first year and 1.2 to $2.2 \mathrm{~mm}$ during the second year of life, IOL in infant is avoided. For that reason we performed IOL surgery at three years or above.

In infant and children there is a greater chance of post operative complications due to fibrinotic reactions. To prevent these reactions, surface coated IOL or addition of low molecular weight (LMW) heparin to irrigation fluid had been advocated. ${ }^{3}$ However, the same was not used in the present study due to either non availability or non affordability.

Visual outcome in such eyes is dependent on many factors such as age of trauma, extent of trauma, duration of trauma prior to IOL surgery, quality of primary repair, accuracy of IOL power calculation, associated complications and visual rehabilitation following cataract surgery. In the present series, $60 \%$ of children had trauma between 3-6 years and 33\% above six years of age. This suggests more development of amblyopia. However, care was taken not to expose these eyes to prolonged visual deprivation by performing early cataract surgery. This could be attributed to very low percentage of development of amblyopia.

Incidence of pupillary capture of any form was comparable to that found in literature. ${ }^{6-19}$ The pupillary capture in our study was neither related to length of the trauma nor associated with inflammation. But it was directly related to the nature and extent of lenticulo-iridio 
Kumar et al. Safety of Primary Intraocular Lens Insertion in Unilateral Childhood Traumatic Cataract

Table 1. Posterior capsular opacification*

\begin{tabular}{ccccccccc}
\hline Type & \multicolumn{2}{c}{ At eighth week } & \multicolumn{2}{c}{ At six months } & \multicolumn{2}{c}{ At 12 months } & \multicolumn{2}{c}{ At three years } \\
& PPC & NPPC & PPC & NPPC & PPC & NPPC & PPC & NPPC \\
& $(\mathrm{n}=57)$ & $(\mathrm{n}=57)$ & $(\mathrm{n}=30)$ & $(\mathrm{n}=39)$ & $(\mathrm{n}=20)$ & $(\mathrm{n}=36)$ & $(\mathrm{n}=28)$ & $(\mathrm{n}=42)$ \\
\hline I & 1 & 2 & 2 & 1 & 2 & 3 & 2 & 4 \\
II & - & 2 & 3 & 5 & 1 & 6 & 2 & 8 \\
III & - & - & 2 & 8 & 1 & 2 & 1 & 3 \\
\hline
\end{tabular}

*Posterior capsular Opacification (PCO):

Type I: Fundus not visible in the central visual axis but seen when pupil is dilated

Direct ophthalmoscopy - normal fundal view.

Type II: Fundus visible in central visual axis

Direct ophthalmoscopy - minimally obscured fundal view

Type III: Fundus visible in central visual axis

Direct ophthalmoscopy - totally obscured fundal view.

Table 2. Visual acuity

\begin{tabular}{|c|c|c|c|c|c|c|}
\hline Visual acuity at different points of time & PL-PR & $<3 / 60$ & $3 / 60-<6 / 60$ & $6 / 60-6 / 24$ & $6 / 18$ & $6 / 12-6 / 6$ \\
\hline Pre operative $(n=114)$ & 98 & 16 & - & - & - & - \\
\hline At discharge UCVA $(n=114)$ & - & 54 & 30 & 6 & 18 & 6 \\
\hline At $8^{\text {th }}$ week BCVA $(n=114)$ & - & 15 & 28 & 14 & 33 & 24 \\
\hline At 6 month $^{*}$ BCVA $(n=89)$ & - & - & 5 & $20^{*}$ & 14 & 50 \\
\hline At 1 year $^{*}$ BCVA $(n=66)$ & - & 2 & 2 & $16^{*}$ & 8 & 38 \\
\hline At 3 years $^{*}$ BCVA $(n=79)$ & - & 4 & 6 & $11^{*}$ & 15 & 43 \\
\hline
\end{tabular}

${ }^{*}$ After membranectomy/ capsulotomy

Table 3. Outcome following traumatic cataract surgery

\begin{tabular}{|c|c|c|c|c|c|c|c|}
\hline Authors and year & $\begin{array}{l}\text { No of } \\
\text { eyes }\end{array}$ & $\begin{array}{l}\text { Uveitis } \\
(\%)\end{array}$ & $\begin{array}{c}\text { Pupillary } \\
\text { capture \%) }\end{array}$ & PCO (\%) & $\begin{array}{c}\text { VA } \geq 6 / 18 \\
(\%)\end{array}$ & $\begin{array}{l}\text { Age at } \\
\text { surgery }\end{array}$ & $\begin{array}{c}\text { Mean follow up } \\
\text { (yrs) }\end{array}$ \\
\hline Bienfait et al $1990^{7}$ & 23 & 0 & 9 & 83 & 70 & $0.4-11$ & 6.5 \\
\hline Gupta et al $1992^{8}$ & 22 & 22 & 9 & 27 & 45 & 3-11 & 0.9 \\
\hline Vats \& Banerjee $1993^{9}$ & 23 & 25 & 37 & NA & 57 & 4-12 & NA \\
\hline Koenig et al $1993^{10}$ & 8 & NA & NA & 37 & 87 & 4-17 & 0.8 \\
\hline Menezo et al $1994^{12}$ & 103 & 9 & 8 & 3-18 & 77 & 3 & 4.9 \\
\hline Anwar et al $1994^{11}$ & 15 & $\begin{array}{l}\text { Not } \\
\text { reported }\end{array}$ & Not reported & 40 & 73.3 & $3-8$ & 3.2 \\
\hline Crouch et al $1995^{6}$ & 10 & NA & NA & 53 & 80 & 3-12 & 2.2 \\
\hline Churchill et al $1995^{13}$ & 15 & NA & NA & NA & 63 & $2-15$ & 4.2 \\
\hline Brady et al $1995^{14}$ & 20 & NA & 7 & 60 & 70 & $2-14$ & 1.5 \\
\hline Knight et al $1996^{15}$ & 3 & 12 & 8 & 96 & 66 & $3-5$ & 2.3 \\
\hline Plager et al $1997^{16}$ & 9 & NA & 1 & 100 & 89 & NA & 2 \\
\hline Eckstein et al $1998^{17}$ & 52 & 19 & 35 & 92 & 75 & $2-10$ & 3 \\
\hline Pandey et al $1999^{18}$ & 20 & 45 & 20 & 60 & 85 & $4-10$ & 2.5 \\
\hline Brar et al $2001^{19}$ & 18 & NA & 44 & 83 & 39 & NA & 1 \\
\hline Present study 2005 & 114 & 25.4 & $\begin{array}{c}9 \% \text { Vs } 21 \% \\
\text { (PPC Vs } \\
\text { NPPC) }\end{array}$ & $\begin{array}{c}21 \% \text { Vs } \\
0.8 \% \text { (PPC } \\
\text { v NPPC) }\end{array}$ & $\begin{array}{l}50 \text { at } 8^{\text {th }} \\
\text { week }\end{array}$ & $2-10$ & $1-3$ \\
\hline
\end{tabular}

$\mathrm{NA}=$ Not available 


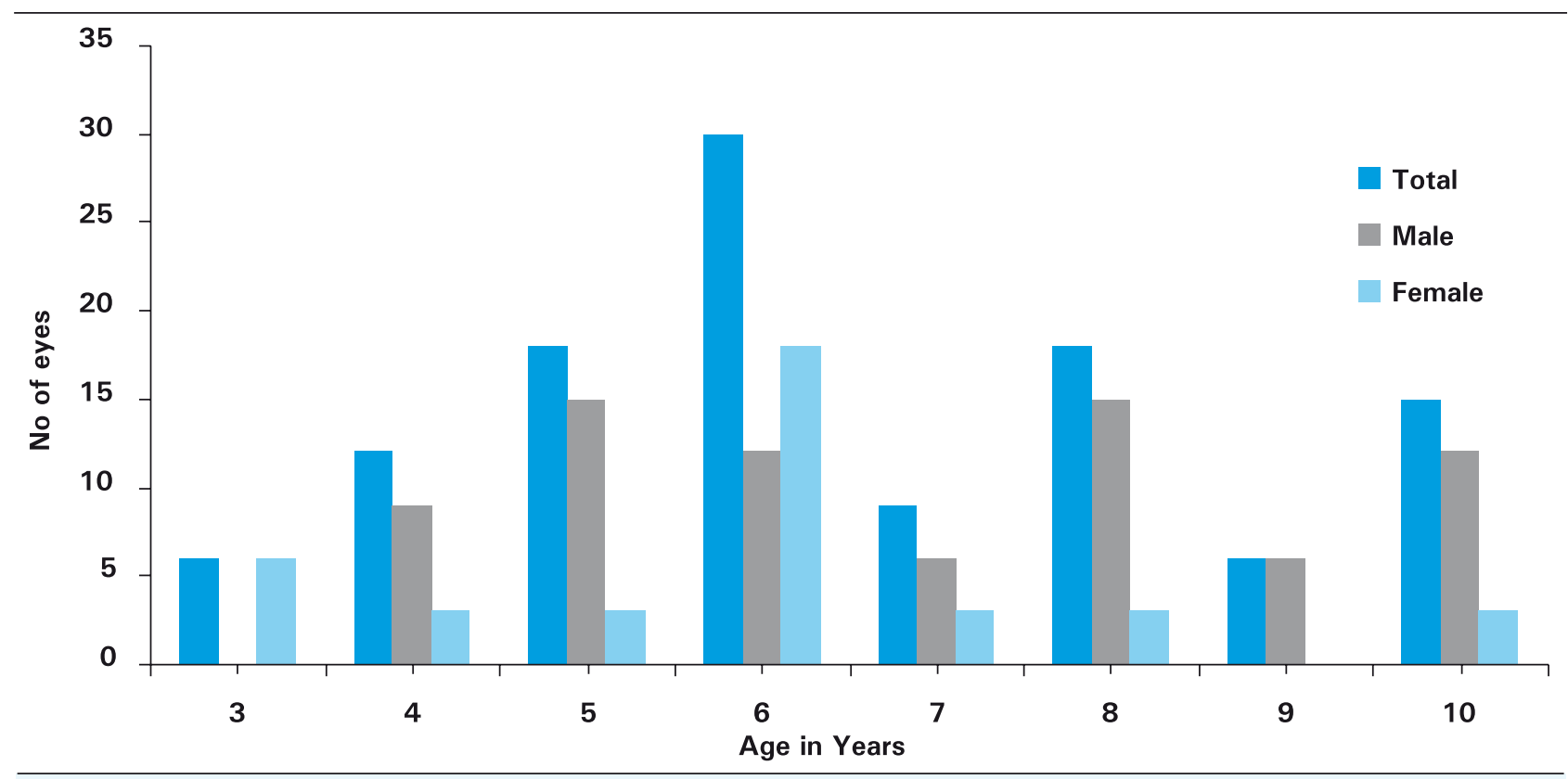

Figure 1. Age \&Gender distribution of traumatic cataract eyes

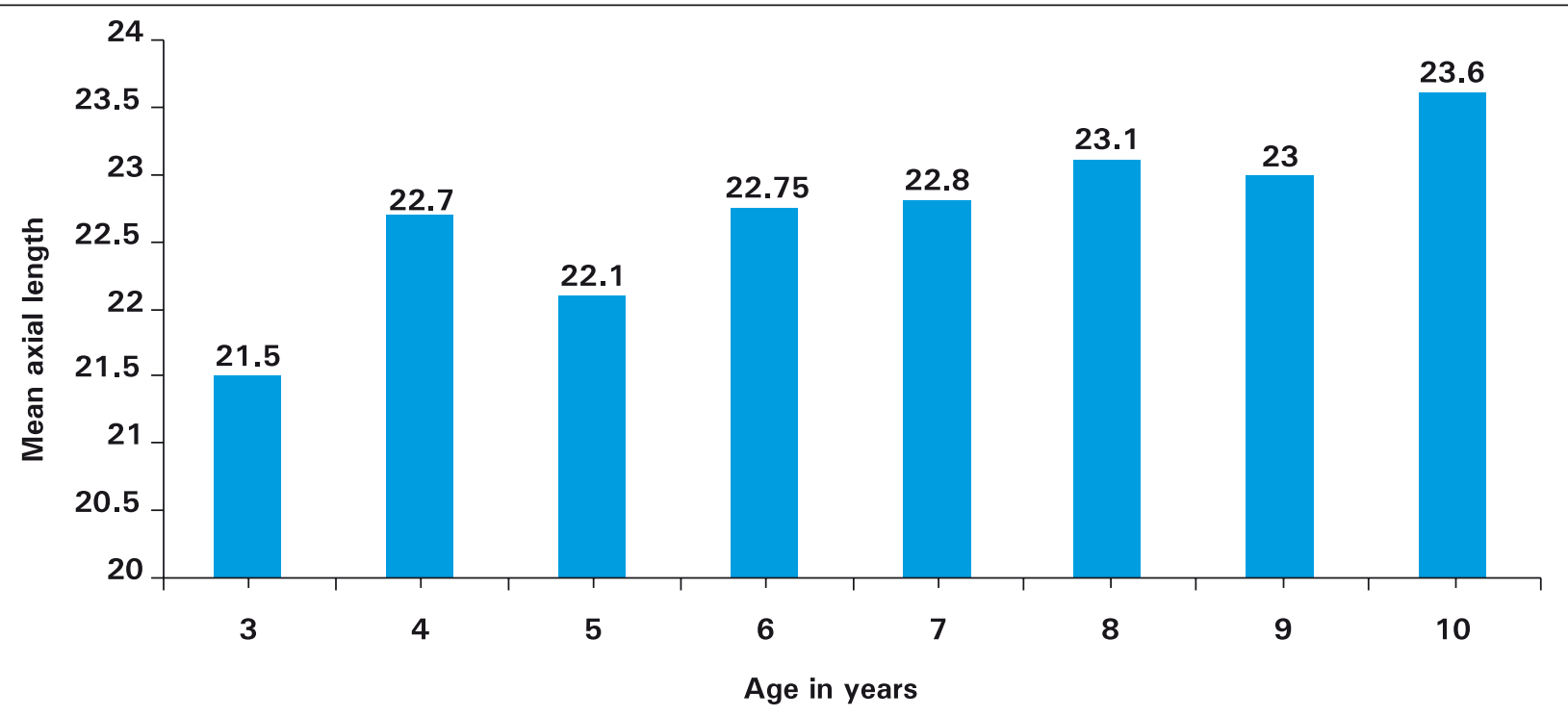

Figure 2. Mean Axial lengths at different age groups

adhesion and capsular opening. Interestingly majority of our pupillary capture were observed in eyes where we performed the IOL insertion in sulcus. To minimize the chances of pupillary capture, avoidance of can opener type of capsulotomy by doing capsulorhexis., use of surface modified IOL's, IOL with forward angulation and large optics have been advocated. ${ }^{20,21}$ We tried to follow the mentioned criteria and put the IOL's in the bag either after capsulorhexis or envelope type capsulotomy as far as possible and used a large optic of $6.0 \mathrm{~mm}$.

Posterior capsular opacification in young children following ECCE is a colossal problem. ${ }^{6-20}$ Primary posterior capsulorrhexis has been advocated to overcome this problem. ${ }^{22} \mathrm{We}$, in our study compared the primary posterior capsulotomy but without optic capture with that of no primary posterior capsulotomy. We observed that we have not introduced any untoward complications to the child's eye by adding one more additional surgical trauma "Primary posterior capsulotomy" to the traumatized eye. Rather it was beneficial to the patients as the development of PCO in this group was much less than NPPC group. However, although our results were comparable to that available in the literature, we found that irregular follow up was the most important limitation in our study. 


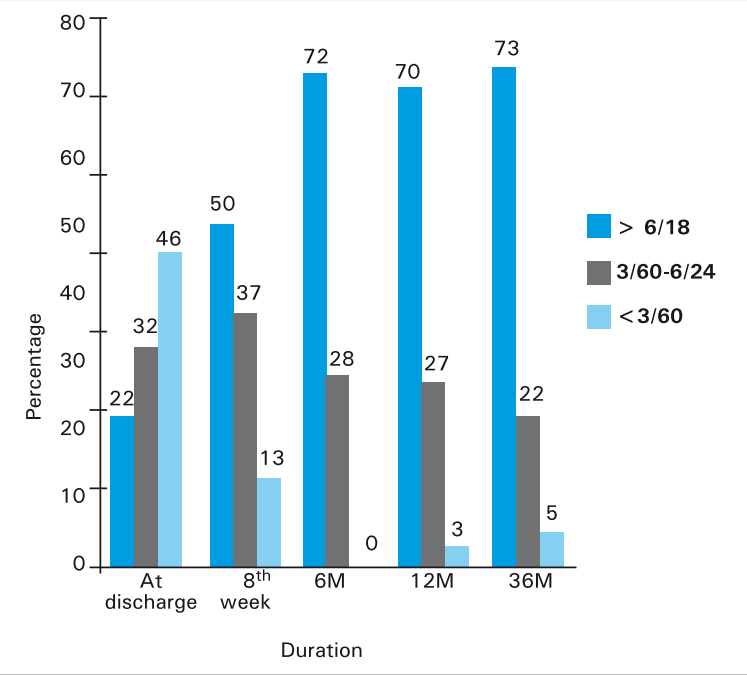

Figure 3. Post operative visual acuity at different time intervals

Excellent visual gain following traumatic cataract surgery in children has been reported in literature with few exceptions..$^{6-19}$ Sub optimal gain in our study could be due to type of IOL fixation (in the bag / sulcus fixated) and method of IOL power calculation (SRK II formula against modern Theoretical formula). Moreover, we have neither used heparin coated IOLs nor added any low molecular weight heparin to irrigating fluid to reduce intense reaction. Nevertheless, it may not be the exact figure as the rate of dropouts was quite high and the percentage was calculated only from the number of patients reported for follow up.
At eastern Nepal, cataract surgery is provided at a nominal charge, both in government (BPKIHS) and nonprofit hospitals. As the general anesthesia facilities are lacking at whole of eastern Nepal except BPKIHS, all the children with traumatic cataract requiring surgical intervention are referred to BPKIHS. Although the eye care services are nominal, the patient incurs substantial expenses in order to access them from distant and hilly areas. The sum total of these costs, including travel, food, medications and loss of earnings, inhibit the parents to bring their children for regular follow up after surgeries unless there is drastic post operative abnormality. This was the most important reason for our irregular follow up.

\section{CONCLUSION}

Capsulorhexis/envelope type of capsulotomy, in the bag IOL with large optic, primary posterior capsulotomy and additional dexamethasone at the end of surgery go a long way for optimal outcome in traumatic cataract surgery in paediatric age group. Early surgery, effective and prompt visual rehabilitation also minimize the chance of development of amblyopia. Finally, this study, though suggested that the results obtained were quite encouraging, it is mandatory to well motivate the parents to bring the children for regular follow up after cataract surgery to know the exact long term situations thus avoiding development of irreversible blindness from reversible blindness for which parental co-operation is essential.

\section{REFERENCES}

1. Binkhorst $\mathrm{CD}$. Post traumatic artificial lens implantation in children. Br J Ophthalmol 1969;53:518.

2. Okihin N. Fibrin reaction following posterior chamber lens implantation. Implants in Ophthalmol 1988;2:216.

3. Angra SK, Ahmed A, Panda A, Vajpayee RB. Role of low molecular weight heparin in paediatric cataract surgery. Visiscan 1996;5:47-54.

4. Elsas FJ. Visual acuity in monocular paediatric aphakia. J Paed Ophthalmol Strabismus 1990;27:304-9.

5. Arffa RC, Marvelli H, Morgan KS. Long term follow up of refractive \& keratometric results of paediatric epikeratophakia. Arch Ophthalmol 1986;104:668-70.

6. Crouch ER Jr, Pressman SH, Crouch ER. Posterior chamber IOL. J Paed Ophthalmol Strabismus 1995;32:210-8.

7. Bienfait MF, Pameijer JH, Wildervanck de Blécourt-Devilee M. IOL in chidren with traumatic cataract. Int Ophthalmol 1990;14:271-6.
8. Gupta AK, Grover AK, Gurha N. Traumatic cataract surgery with IOL in children. J Paed Ophthalmol Strabismus 1992;29:73-8.

9. Vats DP, Banerji A. IOL in paediatric age group. Afro Asian J Ophthalmol 1993;12:338-41.

10. Koening SB, Ruttum MS, Lewandowski MF. Pseudophakia for traumatic cataract in children. Ophthalmology 1993;100:121824.

11. Anwar M, Bleik JH, von Noorden GK, el-Maghraby AA, Attia F. Posterior chamber lens implantation for primary repair of corneal lacerations and traumatic cataracts in children. J Pediatr Ophthalmol Strabismus 1994;31:157-61.

12. Menezo JL, Taboada J. Assessment of intraocular lens implantation in children. J Am Intraocul Implant Soc 1982;8:131-5.

13. Churchil AJ, Boble BA, Etehells DE. Factors affecting visual outcome in children following uniocular traumatic cataract. Eye 1995;9:285-91. 
14. Brady KM, Scott Atkinson C, Kilty LA . Cataract surgery and IOL in children Am J Ophthalmol 1995;120:1-9.

15. Knight Nanan D, O'Keefe M, Bowel R. Outcome and complications of IOL in children with cataract. J Cataract Refract Surg 1996;22:730-6.

16. Plager DA, Lipsky SN, Snyder SK. Capsular management and refractive error in paediatric IOL. Ophthalmology 1997;104:600-7.

17. Eckstein M, Vijaylakshmi P, Killendar M, Gilbert C, Foster A. Use of IOL in children with traumatic cataract $\mathrm{Br} \mathrm{J}$ Ophthalmol 1998;82:911-5.

18. Pandey SK, Ram J, Werner L, Brar GS, Jain AK, Gupta A, et al. Visual results and postoperative complications of capsular bag and ciliary sulcus fixation of posterior chamber intraocular lenses in children with traumatic cataracts. J Cataract Refract Surg 1999;25:1576-84.
19. Brar GS, Ram J, Pandav SS, Reddy GS, Singh U, Gupta A. Postoperative complications and visual results in uniocular pediatric traumatic cataract. Ophthalmic Surg Lasers 2001;32:233-8.

20. Moore BD. The change of refractive error of young children with unilateral congenital cataract. In: Cotlier F, Limbert SR, Taylor D, editors. Congenital cataracts. RG Landes /CRC press, Boca Raton FL, 1994, pp.237-42.

21. Basti S, Ravi Shanker U, Gupta S. Results of a prospective evaluation of paediatric cataracts. Ophthalmology 1996;103:713-20.

22. Gimbel HV, DeBroff BM. Posterior capsulorhexis with optic capture: maintaining a clear visual axis after pediatric cataract surgery. J Cataract Refract Surg 1994;20:658-64. 